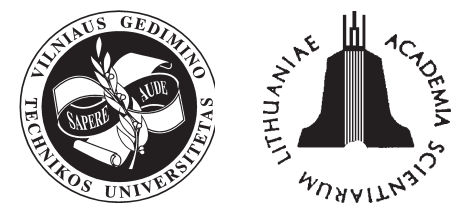

ISSN 1648-4142 TRANSPORT

http:/www.vtu.lt/english/editions

TRANSPORT - 2005, Vol XX, No 2,66-72

\title{
RECTIFIER TRANSFORMERS IN ELECTRIC TRACTION SUBSTATIONS - DIFFERENT DESIGNS
}

\author{
Barbara Kulesz \\ Zaktad Inżynierii Elektrycznej w Transporcie, Instytut Elektrotechniki Teoretycznej i Przemystowej \\ Silesian University of Technology, ul. Akademicka 10, 44-100 Gliwice, Poland. \\ E-mail:bkulesz@polsl.gliwice.pl \\ Received 2004-11-04; accepted 2005-01-25
}

\begin{abstract}
Electric traction in Poland is supplied with de voltage which is obtained from the power grid via traction substations equipped with transformers and rectifiers. The paper gives the results of the investigation of different designs of these transformer-rectfier sets - namely, 12- and 24-pulse systems. The comparison of electrical quantities such as ripple content, harmonic content of supply current and output voltage and utilisation of transformer secondary windings is provided.
\end{abstract}

Keywords: electric traction, energy transformation, rectifiers, transformers, n-pulse systems, harmonic current spectrum.

\section{Preliminary remarks}

The traction network in Poland is supplied with dc voltage. The transformer-rectifier sets present in traction substations transform ac voltage supplied from a power grid into appropriate dc voltage. The simplest version of such appliance consists of a rectifier transformer and a rectifier. Additionally, series reactors are also found in the circuits in some unidirectional rectifier systems as well as cathode reactors in rectifier-transformer sets operating in railway substations [1-6].

The most common rectifier systems used for traction purposes are: pulse),

- six-phase system with series reactor (six-

- bi-directional three-phase system (six-pulse) - most prevalent,

- double bi-directional three-phase parallel system (twelve-pulse),

- double bi-directional three-phase series system (twelve-pulse).

The "n-pulse system" designation refers to the number of pulses (n) of rectified voltage per one period of ac voltage.

\section{Traction substation transformers in Poland}

The development of rectifier transformers is related to the application of $110 \mathrm{kV}$ ac voltage for trac- tion substations supply. A good example can be given by comparing transformer units used in rectifier sets of PK-17/3,3 and PD-17/3,3 types.

PK-17 transformer is a two-winding transformer rated at $4.4 \mathrm{MV} \cdot \mathrm{A}$, with voltage ratio $15 / 2.6 \mathrm{kV}$. Transformer operating with a rectifier set PD-17 has four windings with rated power 7.3/3.15/3.15/1 MV.A respectively and voltage ratio $115 / 1.3 / 1.3 / 16.5 \mathrm{kV}$. Two windings rated at $3.15 \mathrm{MV} \cdot \mathrm{A}$ supply the rectifier, while the winding rated at $1 \mathrm{MV} \cdot \mathrm{A}$ and $16.5 \mathrm{kV}$ supplies substation internal load and non-traction loads. The PD-17 set transformer is equipped with a tap-changer able to operate under load conditions. There are 17 positions of the tap-changer set at $\pm 10 \%$. This makes possible precise adjustment of transformer voltage ratio to supply a voltage level or to control dc rectified voltage. The switching of the tap-changer can be conducted automatically or manually.

Another example of rectifier transformers is the unit used in rectifier set $\mathrm{PD}-1.7 / 3.3$. Its rated power is similar to PD-17 units and equal to $6.3 \mathrm{MV} \cdot \mathrm{A}$ (6.3/ 3.15/3.15 MV·A), but it differs since it is supplied with medium-level voltage.

These transformers are used when traction substation has to be modernised, i.e. the power of rectifier sets has to be increased, and $110 \mathrm{kV}$ ac voltage supply is unavailable for technical or economical reasons. The short-circuit voltage is low and when they are assembled with a rectifier of the parameters similar to those used in sets with one-step voltage trans- 
formation, their output parameters are comparable to those of PD-17 set. The outer dimensions of these transformers make possible putting them in place of PK-17 set transformers, even though their rated power is greater by c. $50 \%$.

\section{N-pulse transformers designs}

Some of the design possibilities for multi-pulse transformers are given below. In most cases one or more bi-directional diode bridge rectifiers (6D) have been used.

a) a twelve-pulse system: one three-winding transformer (one primary winding, two secondary windings) or two two-winding transformers; two rectifiers are connected in series or in parallel,

b) a twenty-four-pulse system: two three-winding transformers where the primary windings are constructed in such a way that secondary voltages vectors are shifted by $15^{\circ}$ in relation to each other; four rectifiers are connected in series or in parallel,

c) a twenty-four-pulse system henceforth called "economical": one three-winding transformer where the primary windings are wye or delta connected and secondary windings are connected in accordance with Fig 1c; four rectifiers.

The transformers connection diagrams are shown in Figs 1a to 1c; to improve the clarity, the windings have been set out as rectangles. The primary windings are designated as U-V-W, the secondary windings are $\mathrm{U} k-\mathrm{V} k-\mathrm{W} k$, where $k$ is an ordinal number of a winding. All these systems are characterised by the fact, that secondary windings are connected in parallel to the traction network via rectifier sets.

The twelve-pulse systems are obtained, if a trans- former is equipped with two independent secondary windings, one of which is wye connected and the other is delta connected (Fig 1a, version I); each winding is connected to the rectifier bridge. The rectifier can be connected in series (railway traction) or in parallel (tram traction). The secondary side voltages are shifted in relation to each other by $60^{\circ}$. In fact this system is nothing else but a double six-pulse system. This can be more clearly observed in Fig 1a, version II where two identical transformers operate with two separate rectifiers.

The twenty-four-pulse system can be designed e.g. with $4 \times 3$ phase transformer (see Fig 1b) where the primary winding is sectioned and the secondary windings are delta and wye connected. The phase shifts for secondary windings are $15^{\circ}$ and $75^{\circ}$.

Delta connection of one of the secondary windings is beneficial because of the non-linear magnetisation curve of a transformer core. The symmetrical components of zero and $3 n$ order close in the delta circuit, this brings about the elimination of magnetic flux due to these components which cause additional losses and noise.

If the windings are sectioned and there is no electrical connection between the sections, they can be connected in parallel without additional reactors.

Since some points of secondary windings of 24pulse transformers are characterised by the same voltage potential at the same time instants, then these points can be electrically connected (see Fig 1c circuit). This transformer can be wound around one single core. The first secondary winding is delta connected and this delta has flattened vertices (Fig 1c). The second secondary winding is wye-connected with two additional windings sections connected into each wye vertex. The phase shifts of secondary voltages are

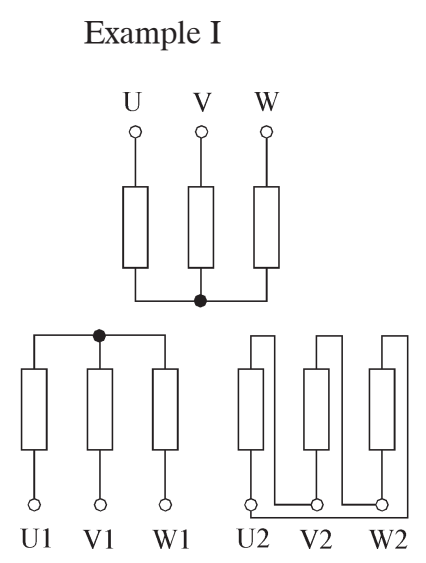

Example II
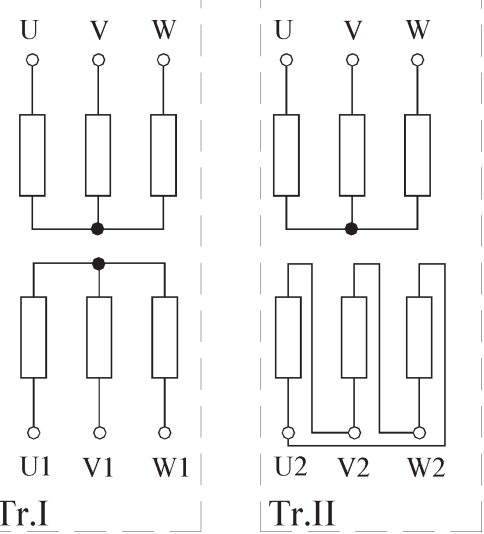

Fig 1a. Examples of 12-pulse transformers designs: version I - three windings transformer, primary winding wye or delta connected; version II - two identical two-winding transformers, the primary winding wye or delta connected (both connected in the same way) 

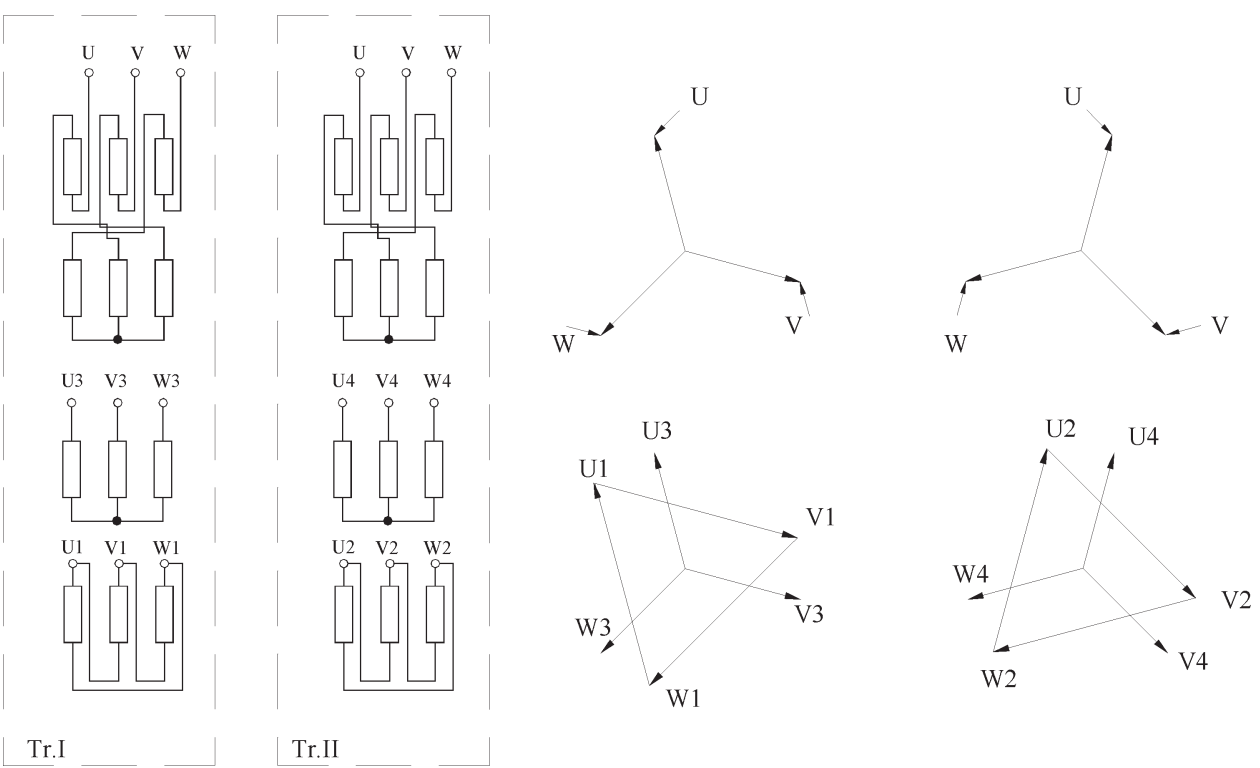

Fig 1b. Example of 12-phase, 24-pulse transformer design (two identical three-winding transformers, with sectioned primary winding); the voltage vectors of different windings are shown on the right
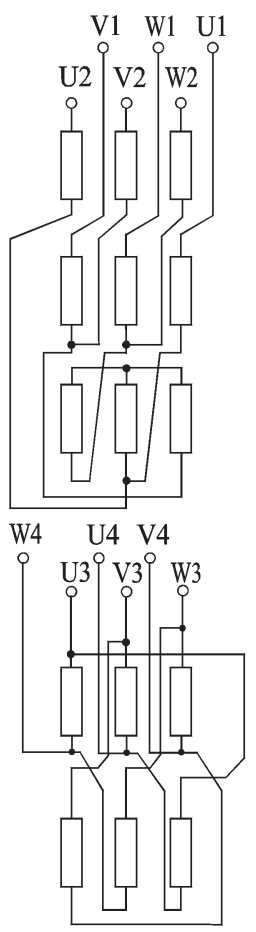

Fig 1c. Example of 12-phase, 24-pulse transformer design with secondary windings connected at some points; the voltage vectors of different windings are shown on the right

equal to $15^{\circ}$ and $105^{\circ}$. Each secondary winding has two sets of three terminals each. The total is twelve terminals $(4 \times 3)$ and the voltage vectors are shifted in relation to each other by $15^{\circ}$. The secondary windings are connected via rectifiers and traction network and interact. This system requires four rectifiers.

\section{Investigation of transformer-rectifier sets}

Simulation and lab measurements of different transformer-rectifier sets have been conducted. The paper presents the results of twelve and twenty-for pulse systems. The assessment of the suitability of different systems has been run basing on the following quantities characterising any given system:

- secondary windings utilisation,

- pulsations of the output voltage,

- higher harmonics of supply current,

- higher harmonics of the output voltage.

The simulation has been run with the help of Pspice A/D software, version 9.1, packet DesignLab. The equivalent parameters of the model transformer have been measured in the laboratory by standard procedures. The measurements have been conducted on the same model transformer.

The model transformer windings are shown in Fig 2.

The secondary windings $(6,7)$ are respectively delta and wye connected, the phase shift between them is equal to $30^{\circ}$. The primary windings (1) are wye connected. the transformer is fitted out with additional groups of windings (4), (5) which make possible the creation of "forked" wye connection and (2) (3) which generate the irregular voltage polygon (delta with flattened vertices) $-c f$. Fig 1c.

The model transformer ratings are $3.3 \mathrm{kV} \times \mathrm{A}$, $3 \times 380 \mathrm{~V}, 12 \mathrm{X} 220 \mathrm{~V}$. 

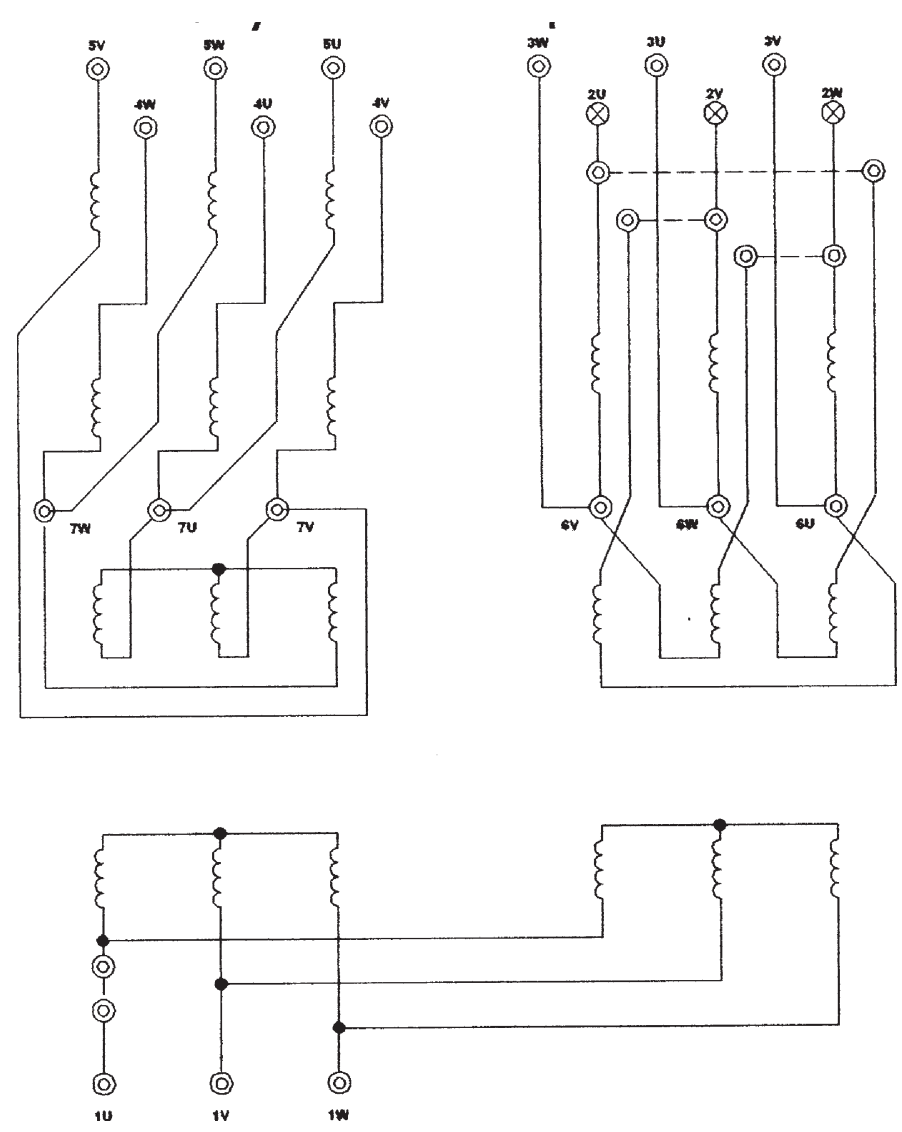

Fig 2. Model transformer windings - description is given in the text

\section{Selected quantities characterising system's opera- tion - definitions}

a) Ripple content of rectified voltage

$$
p=\sqrt{\left(\frac{U_{d s k}}{U_{d}}\right)^{2}-1},
$$

where $U_{d}-$ mean value of rectified voltage, $U_{d s k}-\mathrm{rms}$ value of rectified voltage;

b) Utilisation of transformer secondary windings. This is the ratio of dc power to apparent power of transformer secondary circuit

$$
k_{w s}=\frac{\sqrt{2 m}}{\pi} \sin \frac{\pi}{m}
$$

where $m$ is the number of transformer secondary circuit phases.

\section{Twelve-pulse transformer}

The analysis has been conducted for a transformer with two three-phase groups with wye-to-wye and wye-to-delta connections, respectively (see Fig 3). The rectifier bridges have been connected to P11, P12,
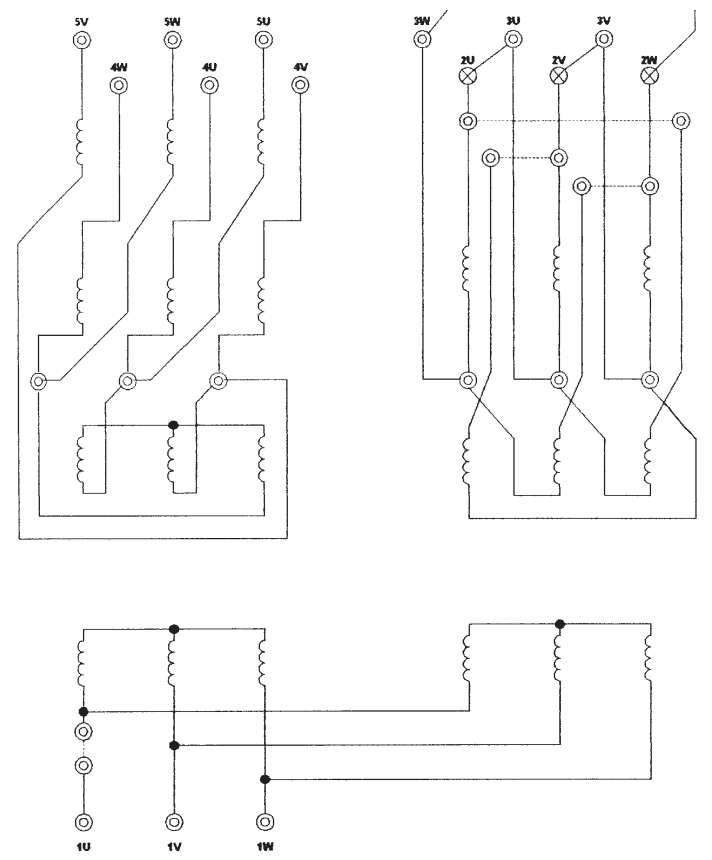

Fig 3. Twelve-pulse transformer connection diagram

P13 and P21, P22, P23 terminals. Rectifier outputs have been connected in parallel. The measurement results (oscillograph) are shown in Figs $4 \mathrm{a}$ and $4 \mathrm{~b}$. 
There were six pulses in the output voltage per one period of ac supply voltage.

The six-pulse effect appears in the circuit where different three-phase groups of secondary windings are electrically connected.

The operation of such system has been simulated and the results are shown in Fig 5. When the load is increased the six-pulse voltage changes into twelvepulse voltage. If the supply voltage is asymmetrical (5\% content of negative phase sequence) and when the time of diode commutation is taken into account then the output voltage course differs even more from the ideal voltage course - see Fig 6. N-per cent asymmetry of the supply voltage is defined as distortion of the symmetrical three phase supply voltage with negative phase sequence voltage and the value of this voltage is equal to $\mathrm{n}$ per cent of positive phase sequence voltage value.

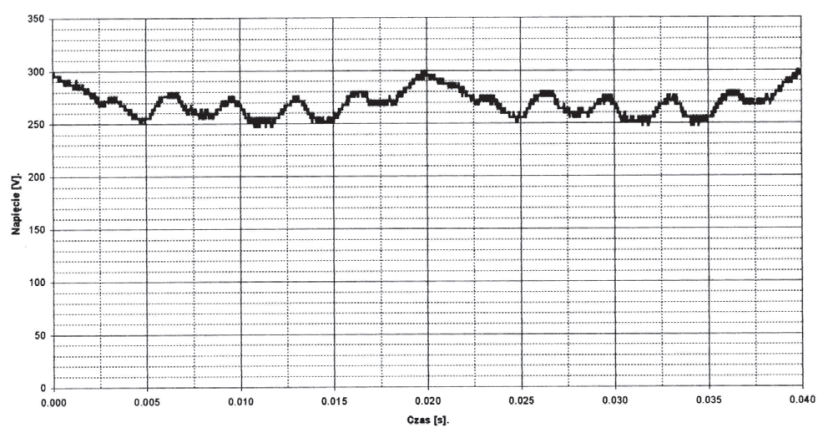

Fig 4 a. Output voltage of a transformer shown in Fig 3

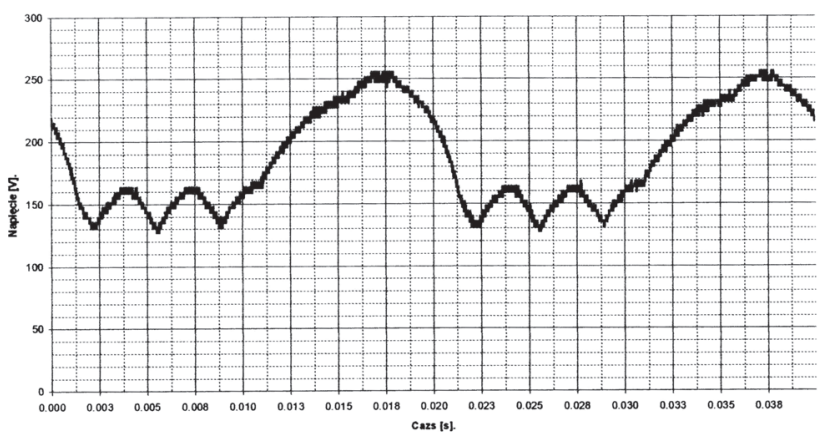

Fig.4 b. Output voltage of a transformer shown in Fig 3 close-up

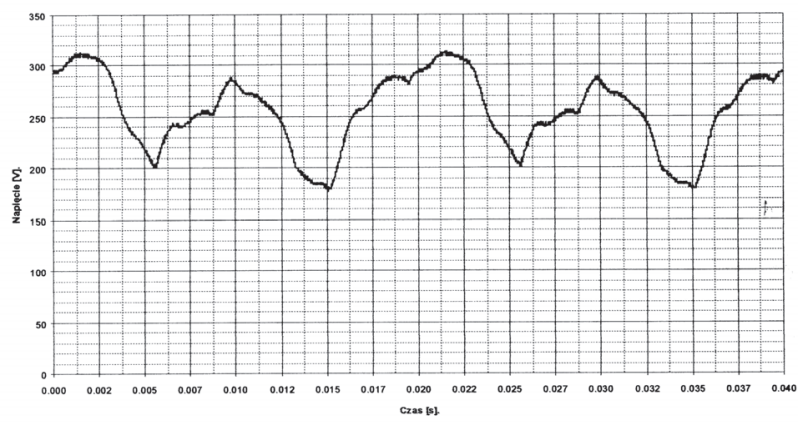

Fig 5. Output voltage of a transformer with connected secondary windings - six-pulse effect observed; measurement result
The simulation results together with Fourier analysis results for output voltage at different supply voltage asymmetry rates are given in Tables 1 and 2 .

The supply current waveform is shown in Fig 7.

\section{24-pulse transformer}

The four three-phase groups of the transformer as shown in Fig 1c are considered (economical system) and the rectifier bridges are connected in parallel.

The output voltage of the loaded circuit is shown in Fig 8 (symmetrical supply voltage) and Fig 9 (asymmetrical supply voltage). The results of simulation are shown in Fig 10.

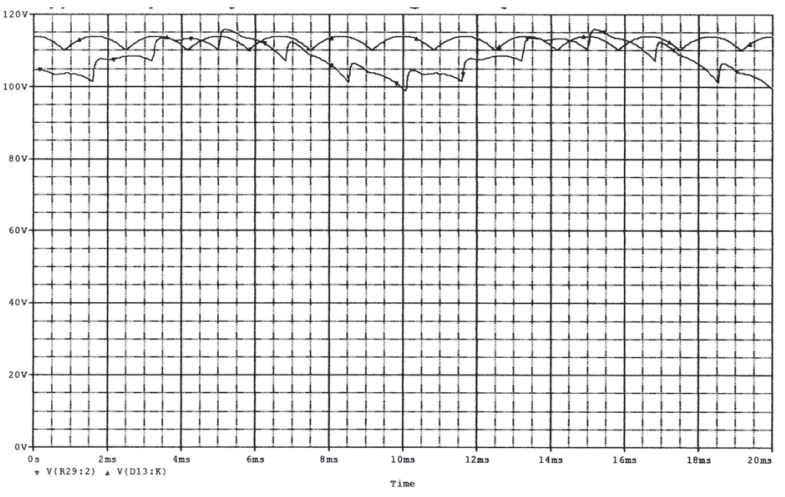

Fig 6. Output voltage vs. time - significant asymmetry of the supply voltage, current commutation is non-instantaneous; simulation results. Ideal voltage course is also shown

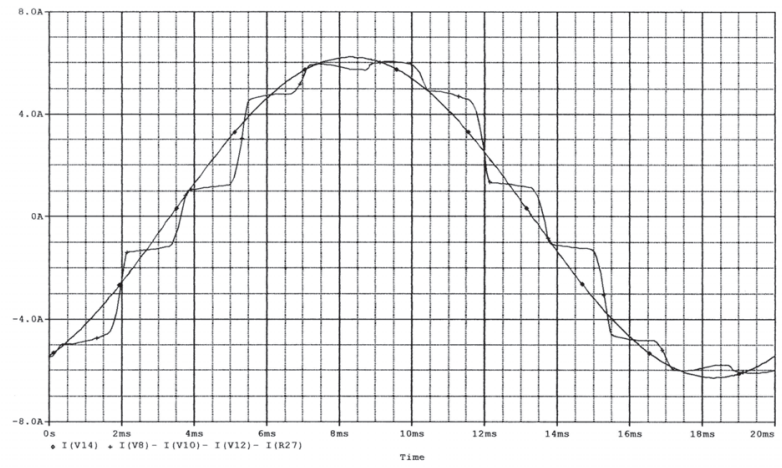

Fig 7. Transformer supply current - simulation

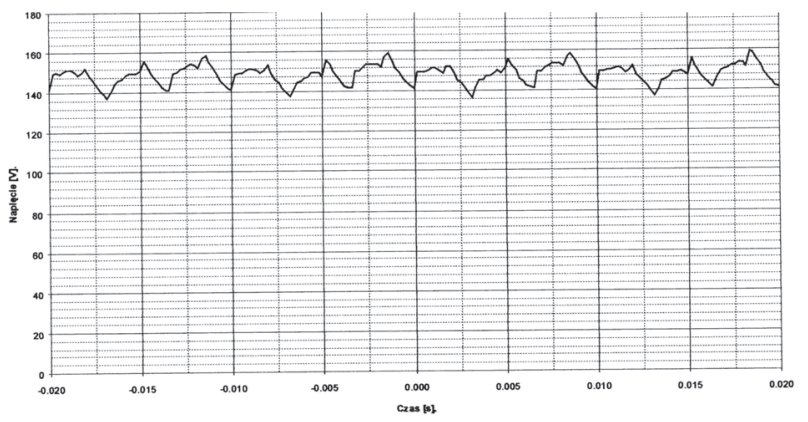

Fig 8. Output voltage of twenty-four-pulse system, symmetrical supply; measurement result (voltage vs. time) 
Table 1.

\begin{tabular}{|c|c|c|c|c|c|c|c|c|c|c|c|c|c|c|c|c|}
\hline \multirow{2}{*}{$\begin{array}{l}\text { Supply voltage } \\
\text { asymmetry rate }\end{array}$} & \multirow{2}{*}{$\begin{array}{c}\text { RMS } \\
\text { voltage, } \\
\text { V }\end{array}$} & \multirow{2}{*}{$\begin{array}{c}\text { Mean } \\
\text { voltage, } \\
\mathrm{V}\end{array}$} & \multirow{2}{*}{$\begin{array}{c}\text { Ripple } \\
\text { content }\end{array}$} & \multicolumn{13}{|c|}{ Higher harmonics content for output voltage, $\%$} \\
\hline & & & & 0 & 2 & 4 & 6 & 8 & 10 & 12 & 14 & 16 & 18 & 20 & 22 & 24 \\
\hline $0 \%$ & 108,29 & 108,28 & 0,014 & 100 & 0 & 0 & 0 & 0 & 0 & 1,4 & 0 & 0 & 0 & 0 & 0 & 1 \\
\hline $1,5 \%$ & 108,31 & 108,29 & 0,018 & 100 & 1,5 & 0 & 0 & 0 & 0,1 & 1,4 & 0 & 0 & 0 & 0 & 0,2 & 1 \\
\hline $5 \%$ & 108,45 & 108,36 & 0,054 & 100 & 5,3 & 0,1 & 0 & 0 & 0,4 & 1,3 & 0,4 & 0,1 & 0 & 0,2 & 0,5 & 0,7 \\
\hline
\end{tabular}

Table 2.

\begin{tabular}{|c|c|c|c|}
\hline $\begin{array}{c}\text { Supply voltage asymmetry } \\
\text { rate }\end{array}$ & Output power, W & $\begin{array}{c}\text { Transformer secondary } \\
\text { circuit apparent power, VA }\end{array}$ & $\begin{array}{c}\text { Utilisation of transformer } \\
\text { secondary circuit }\end{array}$ \\
\hline $0 \%$ & 378,2 & 520,3 & 0,73 \\
\hline $1,5 \%$ & 378,3 & 519,4 & 0,73 \\
\hline $5 \%$ & 378,8 & 520,7 & 0,73 \\
\hline
\end{tabular}

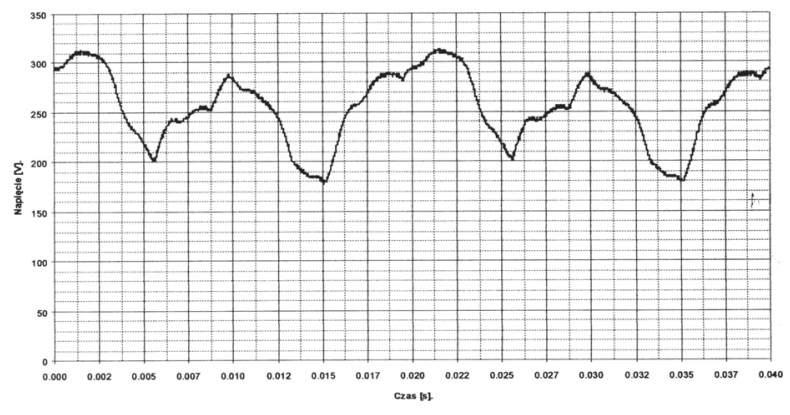

Fig 9. Output voltage of twenty-four-pulse system, symmetrical supply; measurement result close-up (voltage vs. time)

The results of Fourier analysis of the output voltage are given in Table 3 .

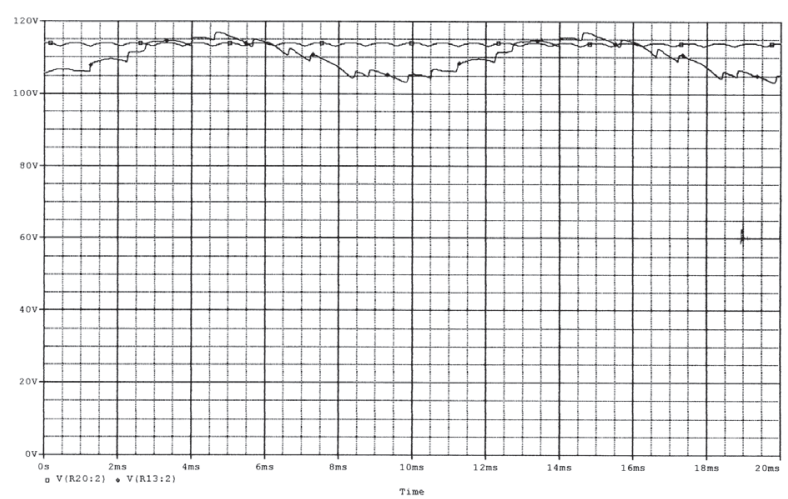

Fig 10. Output voltage vs. time - significant asymmetry of the supply voltage, current commutation is non-instantaneous; simulation results. Ideal voltage course is also shown

Table 3.

\begin{tabular}{|c|c|c|c|c|c|c|c|c|c|c|c|c|c|c|c|}
\hline \multirow{2}{*}{$\begin{array}{l}\text { Supply voltage asymmetry rate, } \\
\text { measurement/simulation }\end{array}$} & \multirow{2}{*}{$\begin{array}{l}\text { Ripple } \\
\text { content }\end{array}$} & \multicolumn{14}{|c|}{ Higher harmonics content for output voltage, $\%$} \\
\hline & & 0 & 1 & 2 & 3 & 4 & 5 & 6 & 7 & 8 & 9 & 10 & 11 & 12 & 24 \\
\hline $0 \%$, meas., no-load & 0,02 & 100 & 2,4 & 1,5 & 0,8 & 0,5 & 0,3 & 0 & 0,1 & 0,1 & 0 & 0 & 0,10 & 0,1 & 0 \\
\hline $0 \%$, simulation, no-load & 0,003 & 100 & 0 & 0 & 0,8 & 0 & 0 & 0 & 0 & 0 & 0 & 0 & 0 & 0 & 0,3 \\
\hline $1,5 \%$, meas., no-load & 0,031 & 100 & 1,1 & 0,4 & 0 & 0,6 & 0,7 & 2,4 & 0,2 & 0,2 & 0,2 & 0 & 0,2 & 0,6 & 0,1 \\
\hline $1,5 \%$, simulation, no-load & 0,011 & 100 & 0 & 1,3 & 0,7 & 0 & 0 & 0 & 0 & 0 & 0 & 0,3 & 0 & 0 & 0,2 \\
\hline $1,5 \%$, meas., load & 0,037 & 100 & 0 & 4,1 & 0 & 0,3 & 0 & 7,6 & 0 & 0,2 & 0 & 0 & 0 & 4,3 & 1,8 \\
\hline $1,5 \%$, simulation, load & 0,011 & 100 & 0 & 1,4 & 0 & 0 & 0 & 0 & 0 & 0 & 0 & 0,1 & 0 & 0 & 0,5 \\
\hline $5 \%$, simulation, load & 0,036 & 100 & 0 & 4,7 & 0 & 0,1 & 0 & 0 & 0 & 0,1 & 0 & 0,4 & 0 & 0,2 & 0,2 \\
\hline
\end{tabular}




\section{Conclusions}

The investigation of 12-pulse and 24-pulse rectifier transformers covered ripple content of output voltage, utilisation of transformer secondary windings, higher harmonics content in the output voltage and supply current. The investigation has been conducted by simulation and measurements.

The ripple content for 12-pulse system is several times higher than for 24-pulse system. For example, if the supply voltage is strictly symmetrical these values are equal to 0,01 and 0,004 respectively (for loaded circuits). As the supply voltage asymmetry is increased the ripple content goes up - for 1,5\% asymmetry these values are equal to 0,018 and 0,011 and for $5 \%$ asymmetry they reach 0,054 and 0,036 , respectively.

When asymmetry is introduced in the supply voltage, the $2^{\text {nd }}$ harmonic starts to appear in the output voltage in the n-pulse system. Its per cent value is approximately equal to the per cent content of negative sequence voltage of the input voltage. When supply voltage asymmetry is increased, the even harmonics start to appear of the ordinals appropriate to a given pulse system. When the asymmetry still goes up, the characteristic number of pulses starts to vanish and the $2^{\text {nd }}$ harmonic value goes up. The mean value of the output voltage remains practically constant.

The utilisation of transformer secondary windings decreases as the number of pulses increases (12pulse system - 0,73, 24-pulse system - 0,68).

The supply current higher harmonics of the $7^{\text {th }}$, $13^{\text {th }}$ and $25^{\text {th }}$ order increase both in 12-pulse and 24pulse systems as the asymmetry in the supply voltage increases (the detailed results have not been included), while $5^{\text {th }}, 11^{\text {th }}$ and $23^{\text {rd }}$ harmonics decrease. Supply current distortion coefficient is equal to c. 12-14\% for 12-pulse transformer and 5-8 \% for 24-pulse transformer.

It seems that from the point of view of the discussed electrical quantities the usability of the presented transformer-rectifier sets for traction purposes is comparable. Further investigation should take into account the consumption of construction materials and the environmental factors such as noise and vibrations.

\section{References}

1. Jezierski, E. Transformers (Transformatory). Warszawa: WNT, 1975 (in Polish).

2. Tunia, H.; Winiarski, B. Energy electronics (Energoelektronika). Warszawa: WNT, 1994 (in Polish).

3. Transformers. The general requirements PN-E06040;1983 (IEC 76;1976) (Transformatory. Wymagania ogólne) (in Polish).

4. Electric machines of rotor type. Nominal parameters. PN-IEC 34-1 (Maszyny elektryczne wirujące. Dane znamionowe i parametry) (in Polish).

5. Researches of the 12-phase 24-pulse transformer. The report executed for ALSTOM firm (Badanie transformatora prostownikowego 12-fazowego 24pulsowego. Raport wykonany przez Pol. Śląską dla firmy). ALSTOM T\&D Transformers sp. z o.o. Gliwice, 2001 (in Polish).

6. Erich, M. Quality of the electric power in schemes with classical converters of an alternating current in a direct current. Master final work (Jakość energii eklektycznej w obwodach z klasycznymi przekształtnikami napięcia przemiennego na stałe. Praca dyplomowa magisterska. Politechnika Śląska). Gliwice, 2002. 